\title{
Accounting for Holdings of Cryptocurrencies in the Slovak Republic: Comparative Analysis
}

\author{
Miriama Blahušiaková
}

\begin{abstract}
Cryptocurrency has attracted more attention recently. With the rapid increase in popularity of cryptocurrencies' transactions it is necessary to adopt a unified approach to this novel, 21st century phenomenon. Since 2009, when the first cryptocurrency Bitcoin was created, thousands of other cryptocurrencies have appeared. As the transactions with cryptocurrencies have increased, national and multinational jurisdictions started to deal with issues concerning taxation and accounting for the cryptocurrency. Multinational jurisdictions and professional institutions differ in their opinions about cryptocurrencies. There are opinions considering cryptocurrency a financial asset, a financial instrument, cash, cash equivalents, inventories or intangible asset. As there is no accounting standard within IFRS specifically addressing cryptocurrency, it is necessary to look at the existing IFRS and apply a principles-based approach. The aim of the paper is to compare the accounting of cryptocurrencies in Slovakia with the requirements and/or recommendations by other standards setters and authorities. Slovakia is selected as it is one of the first countries launching accounting regulation for cryptocurrency. The analysis and comparison are used as the main scientific methods in this study. The IFRS IC in June 2019 concluded that IAS 2 applies to cryptocurrencies when they are held for sale in the ordinary course of business. If IAS 2 is not applicable, holdings of cryptocurrencies should be accounted for under IAS 38. The Slovak Republic is applying different approach to holdings of cryptocurrency, the cryptocurrency is considered the short-term financial asset. Difference between Slovak and multinational solution is even in questions of cryptocurrency's measurement.
\end{abstract}

KEY WORDS: $\quad$ Cryptocurrency, virtual currency, accounting for, IFRS, intangible asset, inventories.

JEL Classification: G23, K33, M40, M48.

University of Economics in Bratislava, Faculty of Economic Informatics, Department of Accounting and Auditing

\section{Introduction}

Cryptocurrency is a subset of crypto assets. There is no legal or commonly accepted definition of cryptoassets. There are various definitions for crypto-assets including the definition from the EU Anti-Money Laundering directive, and the definition from the Financial Action Task Force or from the European Central Bank. Moreover, Leopold and Vollmann (2019) define cryptographic assets as the transferable digital representations that are designed in a way that prohibits their copying or duplication. The technology that facilities the transfer of cryptographic assets is referred to as a "blockchain" or distributed ledger technology.

Correspondence concerning this article should be addressed to: Miriama Blahušiaková, University of Economics in Bratislava, Faculty of Economic Informatics, Department of Accounting and Auditing, Dolnozemská cesta 1, 85235 Bratislava; E-mail: miriama.blahusiakova@euba.sk, +421267295706
European Financial Reporting Advisory Group (EFRAG) defines crypto-asset as a digital representation value or contractual rights created, transferred and stored on some type of distributed ledger technology network and authenticated through cryptography (EFRAG, 2020).

Cryptographic assets can be used for a variety of purposes, including as a medium of exchange of goods and services in on-line shopping, as a medium to provide access to blockchain-based goods or services, and as a way to raise funding for an entity developing activities in this area. Cryptographic asset might be described as either a "token" or a "coin". The difference is based on the asset's functionality but, in practice, the terms can be used interchangeably, because no universally accepted definition of either exists. (Leopold \& Vollmann, 2019) We can't 
agree with this statement because coin is considered to be only one subgroup of tokens. The term "coin" may refer to that kind of cryptographic asset that has the express purpose of acting solely as a medium of exchange. While the term "token" may refer to an asset that gives the holder additional functionality or utility. "Crypto-transaction tokens are usually designed to be easily transferrable, with minimal barriers to acquisition. Value is not derived from some underlying asset, but rather it is determined by a network of users." (Burnie, Burnie and Henderson, 2018)

Leopold and Vollmann (2019) have defined 4 specific subsets of cryptographic assets: cryptocurrency, asset-backed token, utility token and security token. Cryptocurrencies are digital tokens or coins based on blockchain technology, such as Bitcoin. An asset-backed token is a digital token based on blockchain technology that signifies and derives its value from something that dost not exist on the blockchain but instead is a representation of ownership of a physical asset. Utility tokens are digital tokens based on blockchain technology that provide users with access to a product or service, and they derive their value form that right. Utility tokens give holders no ownership in a company's platform or assets and, although they might be traded between holders, they are not primarily used as a medium of exchange. Security token are digital tokens based on blockchain technology that are similar in nature to traditional securities. They can provide an economic stake in a legal entity: sometimes a right to receive cash or another financial asset, which might be discretionary or mandatory; sometimes the ability to vote in company decisions and/or a residual interest in the entity. (Leopold \& Vollmann, 2019)

EFRAG (2020) defines other classification categories of crypto-assets based on combination of the function / business purpose and the economic nature including holder rights that forms the conceptual basis for classification, recognition and measurement of different crypto-assets: payment tokens (cryptocurrencies with no claim on the issuer), E-money tokens (crypto-assets with claim on the issuer that qualify as e-money), payment tokens (stablecoins including Central Bank Digital Currencies), security and asset tokens, utility tokens, hybrid tokens (including some stablecoins), prefunctional tokens, SAFT typically issued with prefunctional tokens.

Holders of crypto-assets become holders by buying them with fiat currency or exchanging with other crypto-assets; from mining activities where miners earn block rewards of new crypt-asset units; as compensation for goods or services; or from airdrops and hard fork events.

One of the most commonly known subgroups of cryptographic assets are cryptocurrencies, which are mainly used as a means of exchange and share some characteristics with traditional currencies. Cryptocurrency (virtual currency, digital currency) can be defined as a digital asset designed to work as a medium of exchange that uses strong cryptography to secure financial transactions, control the creation of additional units and verify the transfer of assets. (Cryptocurrency, 2021) It is based on difficult cryptography algorithm. Nakamoto (2008) describes the electronic coin or cryptocurrency as a chain of electronic signatures whereby each coin's related transactional data is stored in time-stamped virtual "blocks" linked together through a cryptographic process. Lansky (2018) defines cryptocurrency as a system that meets all of the following six conditions:

1. The system does not require a central authority, distributed achieve consensus on its state.

2 . The system keeps an overview of cryptocurrency units and their ownership.

3 . The system defines whether new cryptocurrency units can be created. If new cryptocurrency units can be created, the system defines the circumstances of their origin and how to determine the ownership of these new units.

4. Ownership of cryptocurrency units can be proved exclusively cryptographically.

5. The system allows transactions to be performed in which ownership of the cryptographic units is changed. A transaction statement can only be issued by an entity proving the current ownership of these units.

6. If two different instructions for changing the ownership of the same cryptographic units are simultaneously entered, the system performs at most one of them. 
Short (2014) defines cryptocurrency as a "digital medium of exchange - a digital currency. Cryptocurrency can be thought of as digital 'points' - These points, often referred to as 'coins' can be traded from person to person (peer to peer) to transact value. For value to be transacted, the digital currency itself must have value."

The value of cryptocurrency depends on market and there is no possibility to make new digital currency. Cryptocurrency is characterized by decentralization, and deregulation, simplicity of payments, deflationary character, transactions' anonymity, high volatility and security. Because of its lack of central authority, a cryptocurrency cannot be abolished or regulated by force (Lánsky, 2018). Cryptocurrency does not know the borders and regulations of fiat money. No cryptocurrency is controlled by one central institution (government, Central bank) and no authority can influence the monetary policy. The decentralized control of each cryptocurrency works through distributed ledger technology (blockchain) that serves as a public financial transaction database. Blockchain can be defined as a digital, decentralised ledger that keeps a record of all transactions that take place across a peer-to-peer network and that enables the encryption of information. "The value of blockchain is not only to hold cryptocurrencies but to allow the integration of a huge number of systems over the same platform in a decentralised and secure way" (Lopes \&Alexandre, 2019). Byström (2019) states that in accounting, "blockchains could potentially improve the quality of information reaching investors in two ways: by making the accounting information more trustworthy, and by making the information more timely."

The cryptocurrency is owned by an entity that owns the key that lets it create a new entry in the ledger. Access to the ledger allows the re-assignment of the ownership of the cryptocurrency. The cryptocurrency is not stored on an entity's IT system as the entity only stores the keys to the blockchain. They represent specific amounts of digital resources which the entity has the right to control, and whose control can be reassigned to third parties (Accaglobal, 2019).

Payments realized by cryptocurrency are very fast, with minimum or no payment fees. Transactions are anonymous, which is an advantage on one hand, but it can lead to illegal trades.

Bitcoin is considered the first decentralized cryptocurrency. On October 31st, 2008, an individual or group of individuals operating under the pseudonym "Satoshi Nakamoto" published the Bitcoin Whitepaper and described it as: "a purely peer-topeer version of electronic cash, which would allow online payments to be sent directly from one party to another without going through a financial institution" (Coinmarketcap, 2021). This is why it is thought that the system was originally designed by Satoshi Nakamoto, a mysterious, privacy-obsessed figure who first described the currency's specs in a series of posts on a cryptography e-mail list in late 2008 (Greenberg, 2011).

"Bitcoin itself is defined as a decentralized unit of exchange that facilitates digital peer-to-peer transactions. However, most individuals agree that Bitcoin is not recognized as having intrinsic value other than the trust that individuals place in it" (Albrecht, Hawkins and Duffin, 2020).

Bitcoin works on the peer to peer principle that means that Bitcoin does not use any web servers, it has no central repository. It works in the internet network created by computers of its fans - the miners. The number of cryptocurrency is exactly determined, for example the number of Bitcoins is 21 million. There are more than thousands various virtual currencies, the most popular are Bitcoins, Ether, Ripple, Bitcoin Cash, Stellar, and so on. The cryptocurrency can be received by several ways, by mining, purchasing, creating own cryptocurrency, exchanging for goods or services etc. "Mining activity can be seen as a contest where participants are trying to come first in the competition for the solution of the puzzle, receiving as the prize the block reward and any fees for participants whose transactions were registered in the solved bock" (Dimitri, 2017).

As stated before, the cryptocurrency is characterized by higher volatility. The price of the cryptocurrency can change dramatically over a short time period in either direction and tends to be more unsteady. That is why, it is very difficult to predict the cryptocurrency's price development. In Fig- 
ure 1 (see Figure 1 in the Appendix) we can see the price' swinging of the most popular cryptocurrency - Bitcoin.

There were some authors trying to analyse the bitcoin volatility using various deterministic and probabilistic approaches, for example, Kováč (2019), Ortisi (2016), Mainelli et al. (2019), Abraham (2020), Ma et al. (2020). However, the prediction of cryptocurrency's price is very difficult.

Given rapid increases in value and volatility, the virtual currency has generated a significant amount of interest recently. As activities in cryptocurrencies have increased, it has attracted regulatory scrutiny across multiple jurisdictions. With increasing popularity of cryptocurrencies, it is necessary to adopt uniform attitude to this phenomenon of the beginning of 21 st century. There are many issues concerning accounting, measurement, disclosure, and taxation of cryptocurrencies, but regulation is lacking. The aim of the paper is to compare the accounting for cryptocurrencies in Slovakia with the requirements and/or recommendations by other standards setters and authorities, such as IASB, AASB, IFRS IC, and EFRAG. The Slovak Republic is selected as it is one of the fist countries launching accounting regulation for cryptocurrencies.

\section{Methodology}

The research object of the paper is the virtual currency that firstly appeared in 2009, when the first cryptocurrency Bitcoin was created. There are many other names that can be used for cryptocurrency, such as virtual currency, digital currency, etc. In this paper we consider them synonyms.

Because of the fact, that cryptocurrency is a relatively new issue, printed literary sources dealing with cryptocurrency are limited. We found conference papers from the Slovak researcher Tomás Matuský (Matuský 2017a, 2017b). Other sources we worked with were electronic. There are many internet sources presenting opinions about virtual currency, ofor example Smales (2020), Swan and Filippi (2017), Hazari and Mahmoud (2019), Scharding (2019), Hu et al. (2019), and more. After studying most of them, we presented very brief description of substance and history of cryptocurrency, processed by us in the paper.
Cryptocurrency accounting issues were considered by numerous Czech authors, based on the Australian accountants' research, for example Procházka (2018a, 2018b), Vašek (2018). Procházka (2018b) discussed potential accounting models for cryptocurrencies under IFRS; doing in-depth review of current IFRS accounting guidance he researched that cryptocurrency can fall into multiple categories of assets, such as cash, inventory, investment, and intangible asset. The Ministry of Finance of the Czech Republic issued on the 15th Mai, 2018 the Communication of Ministry of Finance to Accounting for and Presentation of Digital Currencies (Ministry of Finance of the Czech Republic, 2018), in which they state, that current Czech accounting legislation do not contain any amendment of digital currency accounting for. The Ministry of Finance of the Czech Republic recommends to consider digital currency an inventory.

Cryptocurrency measurement is also considered by Berengueres (2018) who researched the valuation of cryptocurrency mining operations using Net Coin Value method.

As cryptocurrencies become a serious contemporary issue, individual countries and their governments, jurisdictions, and other national and international professional institution begin to resolve the emerging consequences on their own.. It was expected that the European Union will prepare some framework for all of the European Union member countries in the area of cryptocurrency definition, measurement, its taxation, accounting for and presentation in the financial statements. But at present, there is still no Standard within IFRS concerning the cryptocurrency.

The paper utilises a comparative study of qualitative nature assessing regulatory frameworks of several standards setters (such as AASB, IASB, IFRS IC, and EFRAG) in comparison with the Slovakia legislation approach. The Slovak Republic was among first countries (if not the first) that legally regulated the taxation and accounting for cryptocurrencies. The paper partially discusses solutions adopted to cryptocurrency in selected countries where are IFRS entities holding cryptocurrencies (e.g., Canada, Japan, France, Lithuania etc.), as well as in the Czech Republic, Hungary, Poland, Austria, and Ukraine - the Slovakia closest neighbours. More attention is 
devoted to the Czech Republic, just because of the fact that the Czech Republic and the Slovak Republic have been one state - Czechoslovakia till 1993, they had the same accounting legislation, so they can have much in common even in the area of holdings of cryptocurrencies.

The main scientific methods used in this paper were analysis and comparison in order to meet the aim of the paper.

\section{Development in Regulation}

In the absence of International Financial Reporting Standards (IFRS) or an Interpretation of the Standing Interpretations Committee - SIC or the International Financial Reporting Standards Interpretations Committee ( IFRS IC or Committee) that specifically applies to a transaction, other event or condition, management must use its judgement in developing and applying an accounting policy that results in information that is relevant and reliable in accordance with IAS 8 Accounting Policy, Changes in Accounting Estimates and Errors. The management of accounting entity is obliged to apply to solvation of a new problem such approach that consider the most recent pronouncements of other standard-setting bodies that use a similar conceptual framework to develop accounting standards. If there is no procedure, the accounting entity creates its own accounting policy that must be described in the notes to the financial statements in detail. It means that if no accounting standard currently exists to explain how cryptocurrency should be accounted for, accountants have no alternative but to refer to existing accounting standards.

Although the first cryptocurrency emerged in 2009 , the topic of cryptocurrencies was identified as a potential new project for the International Accounting Standards Board (IASB) in 2015 through the Board's Agenda Consultation process. However, the Board decided not to act immediately but to continue to monitor developments.

In December, 2016, there was an Accounting Standards Advisory Forum meeting. The Accounting Standards Advisory Forum (ASAF) is an IFRS Foundation advisory forum consisting of representatives from national and supra-national accounting standard setters. The aim of this meeting was to help IASB to create and amend IFRS. The debate was focused on the classification of cryptographic assets from the holder's perspective. One of the items on the agenda was the analysis of need for adjustment of cryptocurrency presentation in the financial statements presented in accordance with IFRS. Discussions continued in various accounting standards boards, but no formal guidance has been issued by the IASB at this point.

For this purpose, the Australian Accounting Standards Board (AASB) prepared a paper whose main author was Henri Venter (Venter, 2016). There are opinions about how to adjust the cryptocurrency within IFRS in this paper. There are four possible variants presented, but neither of them does not provide clear answer on how to consider the cryptocurrency from the accounting point of view. The only thing resulting from this paper is that cryptocurrency should be considered an asset. The authors discussed if the cryptocurrency should be considered a cash or cash equivalents, financial instruments (other than cash), intangible asset or inventory.

Countries, and their regulatory authorities, but also multinational authorities, professional organizations differ in their opinions about cryptocurrencies. Pierre Moscovici, the commissioner of the European Union for economic and financial matters, taxes and duties, in interview of Bloomberg agency at the end of 2017 stated, that European Union studies cryptocurrencies very carefully, but relevant financial authorities do not plan any regulations, restrictions or rules (Gazdarica, 2018).

At the beginning of 2018 European Central Bank claimed governments of European Union member countries to start with regulation and taxation of cryptocurrencies' income. It was because these incomes indicate to be a speculative instrument for money laundering (Gazdarica, 2018). As we can see the European Central Bank and European Commission differed in their opinions about regulation and taxation of cryptocurrencies that time.

At the July 2018 Board meeting, the IASB reached an agreement to ask the IFRS IC to consider guidance for the accounting of transactions involving cryptocurrencies, possibly in the form of an agenda decisions how an entity might walk through the existing IFRS requirements (Leopold \& Vollmann, 2019).

In September 2018, the Committee discussed the application of current IFRS standards to the holdings of 
cryptocurrencies and Initial Coin Offerings (ICOs) as well as the possibility of standard setting activity by the IASB (EY, 2019).

In November 2018, the IASB decided just to monitor the development of crypto-assets and asked the Committee to consider publishing an agenda decision on how entities apply existing IFRS standards to holdings of cryptocurrencies.

In June 2019, the IFRS IC published its agenda decision on "Holdings of Cryptocurrencies." This agenda decision was published as a response to a request from the IASB on how an IFRS reporter should apply existing IFRS standards to its holdings of cryptocurrencies, a subgroup of crypto assets. The IFRS IC noted that a range of cryptographic assets exist. For the purposes of its discussion, the Committee considered a subgroup of cryptographic assets with all the following characteristics that this agenda decision refers to as a "cryptocurrency" (IFRS, 2019a):

a) A digital or virtual currency recorded on a distributed ledger that uses cryptography for security,

b) Not issued by a jurisdictional authority or other party, and

c) Does not give rise to a contract between the holder and another party.

The IFRS IC agenda decision is consistent with the commentary in a 2016 publication by the AASB and a 2018 publication by Chartered Professional Accountants of Canada that noted that cryptocurrencies are not investment property under IAS 40 Investment Property.

In July 2020 the Discussion Paper Accounting for Crypto-Assets (Liabilities): Holder and Issuer Perspective was published by EFRAG. The Discussion Paper is open for constituents' comments for 12 months from July 2020 till 31 July 2021.

\section{Results and Discussion}

According to IFRS Foundation survey performed in July 2019 on financial statements ending 31 December 2018 or later, there was the following number of IFRS Entities holding cryptocurrencies: Australia (6), Canada (42), Hong Kong (6), Isle of Man (1), Japan (1), Jersey (1), South Africa (1), Switzerland (3), Thailand (1), UK (4). (IFRS Foundation, 2019) Unfortunately, the similar survey on financial statements ending 31 December 2019 was not carried out. From this survey, we can see, that only 66 entities - IFRS reporters all over the world hold cryptocurrencies. That means that cryptocurrency was maybe more popular by private persons at that time. Despite this fact, it was necessary to adopt the uniform attitude to accounting treatment of cryptocurrencies.

In the European Union as no IFRS standard concerning cryptocurrency's accounting treatment currently exists, reference must be made to existing accounting standards and perhaps even the Conceptual Framework of Financial Reporting.

As stated before, IASB and IFRS IC started discussion about the holdings of cryptocurrencies in 2018. Many respondents participated at this discussion and their opinions about cryptocurrency varied. A few standards came to mind when considering the accounting for cryptocurrencies held by an entity for its own account.

It might appear that cryptocurrency should by accounted for as cash because it is a form of digital money. Some respondents of the discussion considered cryptocurrencies can be used as a medium of exchange in certain transactions and so meet the definition of cash. One respondent suggested the IASB consider a project to review and update the definition of cash in IFRS (IASPLUS, 2019) IFRS contains no explicit definition of the terms "cash" or "currency". Definition of cash we can find in IAS 7 Statement of Cash Flows (IAS 7) as follows: "Cash comprises cash on hand and demand deposits" (IFRS, 2019b, IAS 7.6). However, for accounting purposes, the terms "cash" and "currency" may seem to be interchangeable. We can see that IAS 32 Financial Instruments: Presentation (IAS 32) makes a connection between currency and cash, and IAS 21 The Effects of Changes in Foreign Exchange Rates (IAS 21) makes a connection between cash, currency and monetary items. However, virtual currencies cannot be considered cash or equivalent to cash as defined in IAS 7 and IAS 32 because they cannot readily be exchanged for any good or service. Although an increasing number of accounting entities are accepting virtual currencies as payment, virtual currencies are not widely accepted as a medium of exchange yet and do not represent legal tender. Entities may choose to accept digital currencies as a form of a payment, but there is no requirement to do so. (Accaglobal, 2019) However, cryptocurrencies do not have some of the common 
properties of cash and currency, especially (Leopold \& Vollmann, 2019):

- Cryptocurrencies are not legal tender and mostly are not issued or backed by any government or state;

- Cryptocurrencies are currently not capable of setting prices for goods and services directly. They might be accepted to settle some transactions, but they are not directly related to the setting of prices for goods or services in an economy.

Another respondents suggested to consider cryptocurrencies cash equivalents. IAS 7 defines cash equivalents as "short-term, highly liquid investments that are readily convertible to known amounts of cash and which are subject to an insignificant risk of changes in value" (IFRS, 2019b, IAS 7.6) Because the cryptocurrencies are subject to significant price volatility, they cannot be classified as cash equivalents.

Other opinions suggested the cryptocurrency should be accounted for a financial asset other than cash at fair value through profit or loss in accordance with IFRS 9 Financial Instruments (IFRS 9). As cryptocurrency does not meet the definition of a financial instrument either because it does not represent cash, an equity interest in an entity, or a contract establishing a right or obligation to deliver or receive cash or another financial instrument. The cryptocurrency does not give its holder a contractual right to receive cash or another financial asset, nor does the cryptocurrency come into existence as a result of a contractual relationship. Cryptocurrency does not provide its holder with a residual interest in the assets of an entity after deducting all of its liabilities. "Cryptocurrency is not a debt security, nor an equity security (although a digital asset could be in the form of an equity security) because it does not represent an ownership interest in an entity" (Accaglobal, 2019). For these reasons, cryptocurrency should not be accounted for a financial asset.

Based on the staff analysis that was agreed in the Committee's November 2018 meeting and the Board's November 2018 meeting, cryptocurrencies do not meet the definition of financial assets in IFRS 9, cash, equivalent to cash or cash equivalents in IAS 7.

Another Standard that could be taken into account was IAS 2 Inventories (IAS 2). IAS 2 defines inventories as assets (IFRS, 2019b, IAS 2.6): a) Held for sale in the ordinary course of business;

b) In the process of production for such sale; or

c) In the form of materials or supplies to be consumed in the production process or in the rendering of services.

IAS 2 does not necessarily require inventories to be in a physical form, but inventory should consist of assets that are held for sale in the ordinary course of business. If an accounting entity holds cryptocurrency for sale in the ordinary course of business which means that entity actively trades the cryptocurrencies, purchasing them with a view to their resale in the near future and generating a profit from fluctuations in the cryptocurrency's price, considering cryptocurrency the inventory might be appropriate.

Thus, one of the conclusions of the IFRS IC' agenda "Holding for cryptocurrencies", that was issued in June 2019, is that if the accounting entity holds the cryptocurrency for sale in the ordinary course of business, holding of cryptocurrency is inventory for the accounting entity within the scope of IAS 2.

If IAS 2 is not applicable, an accounting entity applies IAS 38 Intangible Assets (IAS 38) to holdings of cryptocurrencies. IAS 38 defines intangible assets as "an identifiable non-monetary asset without physical substance" (IFRS, 2019b, IAS 38.8). An asset is identifiable if it is separable or arises from contractual or other legal rights; an asset is separable if it is capable of being separated or divided form the entity and sold, transferred, licensed, rented or exchanged, either individually or together with a related contract, identifiable asset or liability (IFRS, 2019b, IAS 38.12).

The characteristic of non-monetary item we can find in the IAS 21. IAS 21 states that "the essential feature of a non-monetary item is the absence of a right to receive (or an obligation to deliver) a fixed or determinable number of units of currency" (IFRS, 2019b, IAS 21.16).

The IFRS IC observed that holding of cryptocurrency meets the definition of an intangible asset under IAS 38 on the grounds that (EY, 2019):

a) It is capable of being separated from the holder and sold or transferred individually;

b)It does not give the holder a right to receive a fixed or determinable number of units of currency

Holdings of cryptocurrencies can be traded on an exchange and therefore, there is an expectation that 
the entity will receive an inflow of economic benefits. Cryptocurrencies are subject to major variations in price and therefore they are non-monetary in nature. Cryptocurrencies are a form of digital money and do not have physical substance. This is the reason why the most appropriate classification is an intangible asset. (Accaglobal, 2019)

Due to IFRS IC recommendations to accounting treatment of holdings of cryptocurrencies, EFRAG (2020) mentions approaches to holdings of cryptocurrencies in some selected countries, for example:

- IFRS entities in Canada consider holdings of cryptocurrencies intangible assets or inventory,

- IFRS entities in France consider tokens held for own use an intangible fixed asset, tokens held as investments a specific investment category,

- IFRS entities in Japan consider holdings of cryptocurrencies an independent category of assets (a unique asset category). In Japan, an exposure draft on the accounting requirements of Initial Coins Offerings and Security Token Offerings is expected in the first half of 2020,

- IFRS entities in Lithuania consider holdings of cryptocurrencies a financial asset - investment or financial asset held for payment - current financial asset,

- IFRS entities in Switzerland consider holdings of cryptocurrencies a financial asset (current or noncurrent asset), inventory or intangible assets,

- IFRS entities in Netherlands consider holdings of cryptocurrencies an intangible fixed asset, inventory, or other investment.

Here we can see the variety of accounting treatments of cryptocurrencies. The need of unified attitude and solution to cryptocurrencies is thus becoming a very necessary issue.

The Slovak Republic deserves a special interest relating to accounting treatment of cryptocurrency. It is because of the fact, that the Slovak Republic analysed and legally treated issues concerning virtual currency's accounting for, presentation, and especially taxation, much earlier than other countries, IASB or IFRS IC.

The first issue concerning virtual currency in the Slovak Republic was the area of taxes. For the purpose to ensure the uniform interpretation of taxation of incomes coming from virtual currency's sales, the Me- thodical Guidance of the Ministry of Finance of the Slovak Republic No. MF/10386/2018-721 on virtual currency taxation procedures (hereafter referred to as the Methodical Guidance) was issued on the 23rd March 2018.

According to the Methodical Guidance (Ministry of the Finance of the Slovak Republic, 2018a) the virtual currency represents the digital value carrier that is not issued nor guaranteed by Central Bank or Public Authority that is not necessarily bound to any legal tender that has no legal status of currency or cash, but is accepted by some physical or legal entities as a medium of exchange and can be converted, preserved and electronically traded.

On the 1 October, 2018 the Act No. 213/2018 Coll. on Insurance Tax came into effect in the Slovak Republic. This act amended the Act No. 431/2002 Coll. on Accounting as amended (hereafter referred to as the Act on Accounting) and Act No. 595/2003 Coll. on Income Tax as amended (hereafter referred to as the Act on Income Tax). Also, the Decree of the Ministry of Finance of the Slovak Republic No. MF/015328/2018-74 of 19 September 2018 (Ministry of the Finance of the Slovak Republic, 2018b) amending the Decree of the Ministry of Finance of the Slovak Republic No. 23054/2002-92 of 16 December 2002 laying down details of the accounting procedures and the framework for the chart of accounts for entrepreneurs maintaining accounts under the system of double entry bookkeeping (hereafter referred to as the Accounting Procedures for Entrepreneurs) came into effect. Amendments of the Act on Accounting and Accounting Procedures for Entrepreneurs introduced the way of identification, measurement, accounting for and presentation of virtual currency in the Slovak accounting legislation for the first time for entities under Slovak accounting legislation. It is important to say, that there are accounting entities in the Slovak Republic that are IFRS reporters. They must follow recommendations of IASB for accounting treatment of virtual currency (cryptocurrency). The amendment of Act on Income Tax contains mainly the regulations concerning taxation of virtual currency's transactions. Thus, the Slovak Republic belongs to first countries that regulated the identification, measurement and taxation of the virtual currency's transactions. 
Virtual currency is considered, according to the legislation that came into effect in 2018 in the Slovak Republic, a short-term financial asset. Only these cryptocurrencies are considered a short-term financial asset:

- Cryptocurrency purchased for fiat currency,

- Cryptocurrency acquired by mining as of the day of its exchange for goods or services, and

- Cryptocurrency exchanged for other cryptocurrency.

As follows from the above, if holder of cryptocurrency acquires cryptocurrency by mining, this cryptocurrency is not considered a short-term financial asset until its exchange for goods or services. Till that time, the cryptocurrency is reported on off- balance sheet accounts. Transactions with virtual currencies are accounted for through Income Statement as financial income or financial expenses.

It is very necessary to mention that decision for accounting for and presenting the virtual currency as the short-term financial asset came in time, when there was no official decision for holdings of cryptocurrencies on international level. This decision was based on the fact that virtual currency is a form of digital money and can be used as a medium of exchange in certain transactions, despite the fact that there are many countries which do not accept virtual currency as a medium of exchange and that virtual currency does not represent legal tender. We cannot agree with this concept, better solution would be consider the virtual currency a cash in this case. Another reason for considering virtual currency a short-term financial asset was the fact that some holders buy the virtual currency for the purpose to generate a profit from fluctuations in the price. IFRS IC considers this kind of cryptocurrency an intangible asset. Slovak accountancy also does not take into account that virtual currency can be bought for investment purposes. In the Slovak Republic we can notice the same approach to cryptocurrency as we can see in IFRS IC agenda decision - from the holders of cryptocurrency point of view. The Slovak accounting legislation does not treat other subgroups of crypto-assets, such as crypto-assets other than cryptocurrency held for own account, or crypto-assets held on behalf of third parties. It is probable that we can expect review of this initial decision in the way of IFRS IC' recommendations, or other IASB treatments that will result from ongoing discussion. In the nearest future there might be an amendment of existing legislation in the Slovak Republic accomplished.

We find important to mention approaches to cryptocurrencies in countries neighbouring Slovakia. Despite various reasons for holdings and use of cryptocurrencies, the Ministry of Finance of the Czech Republic recommends the uniform accounting for and disclosure of digital currencies in all types of accounting entities, the cryptocurrency is considered an inventory. Poland and Hungary, have no accounting regulations relating to cryptocurrency. In 2017 the Polish National Bank and the Financial Supervision Commission issued a warning against investing in virtual currencies, citing price volatility and the risk of fraud. In April 2018 the Ministry of Finance in Poland published guidance on the tax effects of trading in cryptocurrencies. In Hungary, the National Bank of Hungary warned consumers that using virtual currencies have many risks. But there is no accounting treatment for transactions with cryptocurrencies. Austrian Ministry of Finance qualifies cryptocurrencies as other intangible commodities. Cryptocurrencies are treated like other business assets for income tax purposes, but there is no accounting treatment for cryptocurrency. The Austrian National Bank does not qualify bitcoin as a currency, because it does not fulfil the typical functions of money. From July 2019 to July 2020, Ukraine was recognized as the world leader in the global index of cryptocurrency acceptance. (Kostyuchenko, Malinovskaya and Mamonova, 2020) An important event in the recognition of cryptocurrency was the adoption of the Law of Ukraine "On Prevention and Counteraction to Legalization of Proceeds from Crime, Terrorist Financing and Financing the Proliferation of Weapons of Mass Destruction". The main goal of this law was to prevent money laundering and terrorist financing. Accounting treatment for cryptocurrency in Ukraine is determined by the IFRS IC Agenda Decision, thus cryptocurrency is considered an intangible assets or inventory.

Regarding the measurement of cryptocurrencies, it is necessary to distinguish, which IFRS the entity applies to holdings of cryptocurrency. According to IFRS IC agenda decision if cryptocurrency meets the definition of intangible assets, the cryptocurrency 
should be measured either under cost model or revaluation model. Using the cost model, cryptocurrency is measured at cost on initial recognition and at cost less accumulated amortization and impairment losses on subsequent measurement. Using the revaluation model, cryptocurrency is measured at cost on initial recognition and at fair value less any accumulated amortization and impairment. The revaluation model can be used if an active market for cryptocurrency exists. In accordance with IAS 38, the same measurement model should be used for all assets in a particular asset class. However, if there are cryptocurrencies for which there is no active market in a class of cryptocurrencies measured using the revaluation model, then these cryptocurrencies should be measured using the cost model.

Applying revaluation model, IFRS 13 should be used to determine the fair value of the asset (cryptocurrency). As the Bitcoins are traded on daily basis, it is easy to demonstrate that for this cryptocurrency an active market exists. A quoted market price in an active market provides the most reliable evidence of fair value.

If the cryptocurrency meets the definition of intangible asset, an entity should assess whether the cryptocurrency's useful life is finite or indefinite. It appears that cryptocurrencies as an intangible assets should be considered to have an indefinite useful life because there is no foreseeable limit to the period over which the asset is expected to generate net cash inflows for the entity. Thus, cryptocurrency is not amortized but must be tested for impairment annually.

Cryptocurrencies held for sale in the ordinary course of business are treated as inventories. They are measured at cost on initial recognition and at lower of cost and net realizable value on subsequent measurement. If the entity acts as a broker-trader of cryptocurrencies, then IAS 2 states that inventories (cryptocurrencies) should be measured at cost on initial recognition and at fair value less costs to sell on subsequent measurement.

EFRAG's Discussion Paper provides brief summary of possible initial and subsequent measurement approaches related to crypto-assets based on Standard the entity applies to crypto-assets. This summary is based on IFRS IC agenda decision, National Standards Settlers and accounting firms 'guidance.
Crypto-assets are measured at cost on initial measurement. As of the balance sheet day, there are many possibilities for measurement of crypto-assets depending on applying standard, such as fair value less any accumulated amortisation and impairment (IAS 38 - Revaluation model), cost less any accumulated amortisation and impairment (IAS 38 - Cost model), fair value less costs to sell (IAS 2 - Commodity broker-trader exception), lower of cost and net realisable value (IAS 2 - Other), FVPL or FVOCI or amortised cost (IFRS 9), cost or FVPL or FVOCI (non-financial asset investments or commodities investment). If the crypto-assets is classified as a unique asset (e. g. Japan), initial measurement is not prescribed, and subsequent measurement is FVPL, if active market exist, or historical cost (inactive market).

In the Czech Republic, the cryptocurrency is measured either at acquisition cost, at conversion cost or at replacement cost depending on the way of their acquisition on initial recognition. As of the balance sheet date, the entities are obliged to consider all impairment relating to cryptocurrencies, which shall be expressed by means of value adjustments if there is a justified assumption of impairment of a cryptocurrency below its carrying amount.

According to the Slovak accounting legislation, the virtual currency is measured at fair value on initial recognition. Fair value of the virtual currency, that is considered to be the short-term financial asset, is the market price as of the date of the accounting transaction acquired by the accounting entity from the chosen public market with the virtual currency. The fair value of virtual currency is not adjusted as of the balance sheet date. This is also very questionable issue, as the short-term financial asset such as shares and securities held for trading are measured as of the balance sheet date at new fair value acquired from the active market, stock exchange etc. Despite this fact, the virtual currency nowadays is not adjusted and the changes in market value influence profit or loss at the moment of selling this virtual currency, at the moment of changing virtual currency for another virtual currency or at the moment of changing virtual currency for goods or services. Presentation of virtual currency in historical cost in the statement of financial position can lead either to underestimation or overestimation of assets in the statement of financial 
position according to changes of virtual currency's market prices.

Here we also can see the difference between measurement of cryptocurrency in accordance with IFRS and Slovak accounting legislation. While IFRS admit to adjust the value of cryptocurrency as of the balance sheet day in both directions (increasing and also decreasing in value) depending on the measurement model the accounting entity uses, cryptocurrency in the Slovak republic is measured on subsequent measurement at the same fair value it was measured on initial measurement.

As required by IAS 1 Presentation of Financial Statements, an accounting entity is required to disclose any additional information that is relevant to an understanding of its financial statements, in notes to the financial statements. The following disclosure requirements should be presented in notes to the financial statements in the context of holdings of cryptocurrencies:

- The disclosures required by IAS 2 for cryptocurrencies held for sale in the ordinary course of business;

- The disclosures required by IAS 38 for holdings of cryptocurrencies to which it applies IAS 38;

- If an accounting entity measures holdings of cryptocurrencies at fair value less costs to sell, IFRS 13 specify applicable disclosure requirements;

- An accounting entity discloses judgements that its management has made regarding its accounting for holdings of cryptocurrencies, if they are part of the judgements that had the most significant effect on the amounts recognized in the financial statements;

- Under IAS 10 Events after the Reporting Period the accounting entity is required to disclose details of any material non-adjusting events, including information about the nature of the event and an estimate of its financial effect (or a statement that such an estimate cannot be made). An entity holding cryptocurrencies would consider whether changes in the fair value of those holdings after the reporting period are of such significance that non-disclosure could influence the economic decisions that users of financial statements make on the basis of the financial statements.

In the Slovak Republic, there are no extra requirements for cryptocurrency's disclosure. Despite this fact, we recommend to disclose in the notes to the financial statements at least the information about held cryptocurrencies, and information concerning determination of their fair value, especially the active public market from which the market price (fair value) is taken.

As mentioned before, EFRAG published in July 2020 the Discussion Paper concerning Accounting for Crypto-assets (liabilities) focusing not only on accounting for cryptocurrency (held for own account) but also on other subgroups of crypto-assets (liabilities) from holder and issuer perspective. IFRS IC agenda decision was primarily pointed to accounting for holding for cryptocurrencies, whilst other subgroups of crypto-assets were omitted. Holding of some crypto-assets where there is a claim on the issuer (e.g., some stablecoins, security tokens, utility tokens) and the issuance of crypto-assets fell outside the scope of the IFRS IC agenda decision. EFRAG's discussion paper opens possibilities for accounting treatments of all crypto-assets (liabilities), not only for cryptocurrencies held for own account. The aim of the Discussion Paper is to obtain comments from constituents who are welcomed to response "Questions to Constituents." The Discussion paper offers possible approaches to the clarification or development of IFRS requirements for crypto-assets (liabilities), whereas the following three principles could be considered: economic substance including rights and obligations, holder business purpose, and nature of the issuer obligation. The following possible approaches to the way forward may be considered (EFRAG, 2020):

1. No amendment to IFRS Standards (no change in applicable IFRS Standards; entities will apply existing IFRS including having to develop their own accounting policy - IAS 8),

2. Amend and/or clarify existing IFRS Standards (IAS 1, IAS 2, IAS 8, IAS 16, IAS 32, IAS 37, IAS 38, IFRS 9, IFRS 11, IFRS 13, IFRS 15, IFRS 16),

3. A new Standard on crypto-assets/liabilities or digital assets/liabilities (on the premise that cryptoassets/liabilities are unique assets and liabilities).

First approach is based on no change to applicable IFRS Standards, so preparers apply applicable IFRS or develop own accounting policy. The Pros of this approach is in the fact that currently, crypto-assets 
(liabilities) are not pervasive amongst IFRS reporting entities. This approach leads, on the other hand, to diversity in practice and leaves some unresolved aspects in the recognition and measurement of crypto-assets (liabilities).

The second approach can reduce diversity in practice, can result in comparable accounting, can lead to timely response to stakeholder needs but similarly as the first approach, leaves some unresolved aspects related to recognition and measurement of cryptoassets (liabilities), etc.

The third approach could comprehensively provide relevant recognition, measurement, presentation, and disclosure requirements for all crypto-assets (liabilities), but a standalone crypto-assets/digital assets Standard could be perceived as legitimising and enabling the development of risky products. The cons of this approach is also the lengthy due process before a new standard can be developed and has a risk that a new Standard would neither fit well nor complement the current IFRS Standards as it may localise crosscutting issues.

The Discussion Paper deals with other issues related to crypto-assets and opens new possibilities to accounting treatment of all subgroups of crypto-assets. We all will expect adopted conclusions based on discussion of constituents.

\section{Conclusions}

The IFRS IC concluded that IAS 2 applies to cryptocurrencies when they are held for sale in the ordinary course of business. If IAS 2 is not applicable, holding of cryptocurrencies should be accounted for under IAS 38. If an entity actively trades the cryptocurrencies, purchasing them with an intention to their resale in the near future and to generate a profit from fluctuations in the price, the cryptocurrency could not be in the scope of IAS 2. In this case, IAS 38 is applied for holding of cryptocurrencies. Even the Czech Republic's jurisdiction recommends to consider the cryptocurrency the inventory, although there is no legal Standard for cryptocurrency's accounting for. This is the main difference in comparison with the accounting legislation in the Slovak Republic, where the virtual currency is considered the short-term financial asset by legislation. The main reason for considering virtual currency a short-term financial asset, is the fact that the cryptocurrency can be used as the medium of exchange. The second reason is that because of cryptocurrency's volatility, the entity can generate a profit from fluctuations in the price or traders 'margin. The Slovak legislation does not distinguish among cryptocurrency used as the medium of exchange, cryptocurrency purchased with a view to resale, and cryptocurrency used in some other ways, probably as an investment property. It is still considered the short-term financial asset.

It is necessary to underline, that the Slovak Republic was one of first countries that has regulated recognition, measurement and taxation of cryptocurrency by law. First Methodical Guidance regulating the virtual currency's area in the Slovak Republic was issued in March 2018 and was focusing on taxation of incomes flowing from transactions with virtual currencies. Furthermore, in October 2018 several acts, concerning identification, measurement, accounting for and taxation of virtual currency, were amended.

The measurement of cryptocurrency also differs throughout the legislations. While the Slovak accounting legislation recommends to measure the virtual currency at fair value on initial recognition, and at the same fair value on subsequent recognition as of the balance sheet date, the IFRS IC recommends to measure the virtual currency in accordance with the Standard (IAS 2 or IAS 38) an accounting entity applies to holdings of cryptocurrency. The cryptocurrency is measured at cost on initial recognition regardless of the fact, within the scope of which Standard it is. The subsequent measurement of cryptocurrency is either at lower of cost and net realisable value, or fair value less costs to sell, when cryptocurrency is within the scope of IAS 2. On the other hand, when the cryptocurrency is considered the intangible asset under IAS 38, it is measured either at fair value less any accumulated amortization and impairment or at cost less any accumulated amortization and impairment at subsequent measurement. We would recommend to revaluate virtual currency in the Slovak Republic on subsequent measurement at actual fair value, as the market prices are changing very rapidly and presentation of virtual currency at historical cost in the statement of financial position does not express real value (fair value) of accounting entity's assets now. 
As the popularity of cryptocurrency and other crypto-assets is still increasing, and also because the EFRAG's Discussion Paper has been published last year, we can expect that the identification, recognition, measurement, and presentation of the cryptocurrency will be regulated by individual Standard within IFRS soon. It is very necessary to treat all the groups of crypto-assets, not only cryptocurrencies and bring solutions not only from holder point of view, but even from the issuer perspective. Due to worldwide harmonization in accounting area, it is supposed, that the Slovak legislation will be amended soon in accordance with the multinational legislation. The aim of the uniform accounting treatment of cryptocurrency is comparability of information related to cryptocurrencies presented in the financial statement all over the world.

\section{Acknowledgments}

The paper was supported by VEGA No 1/0121/21 Analýza vplyvu krízy súvisiacej s COVID-19 na finančné zdravie subjektov $\mathrm{v}$ Slovenskej republike (The Analysis of Impact of Crises Related to COVID-19 on Financial Health of Entities in the Slovak Republic

\section{References}

Abraham, M. (2020). Studying the patterns and longrun dynamics in cryptocurrency prices. Journal of Corporate Accounting \& Finance, 31(3), 98-113. https://doi.org/10.1002/jcaf.22427

Accaglobal. (2019). Accounting for Cryptocurrencies. https://www.accaglobal.com/in/en/student/examsupport-resources/professional-exams-studyresources/strategic-business-reporting/technicalarticles/cryptocurrencies.html

Albrecht, C., Hawkins, S., \& Duffin, K. M. (2020). Legitimizing Bitcoin as a currency and store of value: Using discrete monetary units to consolidate value and drive market growth. Ledger, 5. https://doi. org/10.5195/ledger.2020.167

Berengueres, J. (2018). Valuation of crypto-currency mining operations. Ledger, 3. https://doi. org/10.5195/ledger.2018.123

Burnie, A., Burnie, J., \& Henderson, A. (2018). Developing a cryptocurrency assessment framework: Function over form. Ledger, 3. https://doi. org/10.5195/ledger.2018.121

Byström, H. (2019). Blockchains, real-time accounting, and the future of credit risk modeling. Ledger, 4. https://doi.org/10.5195/ledger.2019.100

Coinmarketcap. (2021). Bitcoin price evolution till January 2021. Retrieved from: https://coinmarketcap.com/currencies/bitcoin/ (January 2021)

Dimitri, N. (2017). Bitcoin mining as a contest. Ledger, 2, 31-37. https://doi.org/10.5195/ledger.2017.96

EY. (2019). Holdings of Cryptocurrencies. https://assets.ey.com/content/dam/ey-sites/ey-com/en_gl/ topics/ifrs/ey-devel150-cryptocurrency-holdingsaugust-2019.pdf

Gazdarica, M. (2018). Európska centrálna banka vyzýva na reguláciu a danenie kryptomien [European Central Bank calls for regulation and taxation of cryptocurrencies]. https://kryptoportal.sk/ europska-centralna-banka-vyzyva-na-regulaciudanenie-kryptomien/

Greenberg, A. (2011, April 20). Crypto Currency. Forbes. http://www.forbes.com/forbes/2011/0509/ technology-psilocybin-bitcoins-gavin-andresencrypto-currency.html

Hazari, S. S., \& Mahmoud, Q. H. (2019). Comparative evaluation of consensus mechanisms in cryptocurrencies. Internet Technology Letters, 2(3), e100. https://doi.org/10.102/itl2.100

Hu, A. S., Parlour, C. A., \& Rajan, U. (2019). Cryptocurrencies: Stylized facts on a new investible instrument. Financial Management, 48(4), 10491068. https://doi.org/10.1111/fima.12300

IASPLUS. (2019) IASPLUS - Holdings of Cryptocurrencies. https://www.iasplus.com/en/meeting-notes/ ifrs-ic/2019/june/holdings-of-cryptocurrencies

International Financial Reporting Standards. (2019a). IFRS - Holdings of Cryptocurrencies. https://www. ifrs.org/projects/2019/holdings-of-cryptocurrencies/

International Financial Reporting Standards. (2019b). IFRS Standards issued on 1st January 2019. IASB.

International Financial Reporting Standards Foundation. (2019, November). IASB Staff paper - IASB Meeting - Agenda Ref 12J, Project - Cryptoassets, topic - Monitoring activities. https://www.ifrs. org/-/media/feature/meetings/2019/november/ iasb/ap12j-implementation-matters.pdf

Kostyuchenko, V., Malinovskaya, A., \& Mamonova, A. (2020). Legal and accounting dimensions of cryptocurrency in Ukraine. Journal of Economics and Economic Education Research, 21(6), 1-8 https://www.abacademies.org/articles/Legal-and- 
accounting-dimensions-of-cryptocurrency-inUkraine-1533-3604-21-6-203.pdf

Kováč, S. (2019). Bitcoin volatility analysis: Deterministic and probabilistic approach. Ekonomické Rozhlady: Vedecký Časopis Ekonomickej Univerzity V Bratislave, 48(4), 375-387.

Lansky, J. (2018). Possible state approaches to cryptocurrencies. Journal of Systems integration, 9(1), 19-31 http://www.si-journal.org/index.php/JSI/ article/viewFile/335/325

Leopold, R., \& Vollmann, P. (2019). In depth. A look at current financial reporting issues. Cryptographic assets and related transactions: accounting considerations under IFRS. PWC.

https://www.pwc.com/gx/en/services/audit-assurance/assets/pwc-cryptographic-assets-and-related-transactions-accounting-considerations-under-ifrs.pdf

Lopes, V., \& Alexandre, L. A. (2019). An overview of blockchain integration with robotics and artificial intelligence. Ledger, 4. https://doi.org/10.5195/ ledger.2019.171

Ma, F., Liang, C., Ma, Y., \& Wahab, M. I. M. (2020). Cryptocurrency volatility forecasting: A Markov regime-switching MIDAS approach. Journal of Forecasting, 39(8), 1277-1290. Retrieved from: https://doi.org/10.1002/for.2691

Mainelli, M. R., Leitch, M., \& Demetis, D. (2019). Economic simulation of cryptocurrencies and their control mechanisms. Ledger, 4. https://doi. org/10.5195/ledger.2019.130

Matuský, T. (2017a). Accounting of cryptocurrencies. EDAMBA 2017: conference proceedings: knowledge and skills for sustainable development: the role of economics, business, management and related disciplines: [20th] international scientific conference for doctoral students and post-doctoral scholars: University of Economics in Bratislava, Slovak Republic, 4 - 6 April 2017, 313-321.

Matuský, T. (2017b). Cryptocurrencies under Slovak act on accounting. Accounting and Auditing in the Process of International Harmonization: Proceedings form International Scientific Conference, $\mathrm{Zu}$ berec. University Centre UNIZA, 11 - 13 September 2017, 133-137.

Ministry of Finance of the Slovak Republic. (2018a). Metodické usmernenie Ministerstva financií Slovenskej republiky č. MF/10386/2018-721 k postupu zdaňovania virtuálnych mien [The Methodical Guidance of the Ministry of Finance of the Slovak Republic No. MF/10386/208-721 on Virtual Currency Taxation Procedures]. https://www. mfsr.sk/files/archiv/financny-spravodajca/4577/2/ Usmernenie-k-virtualnym-menam.pdf

Nakamoto, S. (2008). Bitcoin: A Peer-to-Peer Electronic Cash System. https://abitcoin.org/bitcoin.pdf

Ministry of the Finance of the Slovak Republic. (2018b). Opatrenie Ministerstva financií Slovenskej republiky z 19. septembra 2018 č. MF/015328/2018-74, ktorým sa mení a dopĺña opatrenie Ministerstva financií Slovenskej republiky zo 16. decembra 2002 č. 23054/2002-92, ktorým sa ustanovujú podrobnosti o postupoch účtovania a rámcovej účtovej osnove pre podnikatelov účtujúcich $\mathrm{v}$ sústave podvojného účtovníctva $\mathrm{v}$ znení neskorších predpisov. (The Decree of the Ministry of Finance of the Slovak Republic No. MF/015328/2018-74 of 19 September 2018 amending the Decree of the Ministry of Finance of the Slovak Republic No. 23054/200292 of 16 December 2002 laying down details of the accounting procedures and the framework for the chart of accounts for entrepreneurs maintaining accounts under the system of double entry bookkeeping as amended.)

Ortisi, M. (2016). Bitcoin market volataility analysis using grand canonical minority game. Ledger, 1, 111-118. https://doi.org/10.5195/ledger.2016.61

Procházka, D. (2018a). Accounting measurement of investments into cryptocurrencies. Accounting and Auditing in the Process of International Harmonization: Proceedings from International Scientific Conference, Janské Láznè, 4-6 September 2018, Czech Republic, 128-133.

Procházka, D. (2018b). Accounting for Bitcoin and other cryptocurrencies under IFRS: A comparison and assessment of competing models. The International Journal of Digital Accounting Research, 18(24), 161-188. http://www.uhu.es/ ijdar/10.4192/1577-8517-v18_7.pdf

Scharding, T. (2019). National currency, world currency, cryptocurrency: A Fichtean approach to the Ethics of Bitcoin. Business and Society Review, 2(124). https://doi.org/10.1111/basr.12169

Ministry of Finance of the Czech Republic. (2018). Sdělení Ministerstva financí $\mathrm{k}$ účtování a vykazování digitálních měn. (The Communication of Ministry of Finance of the Czech Republic to Accounting for and Presentation of Digital Currencies.)https://www.mfcr.cz/cs/verejny-sektor/ ucetnictvi-a-ucetnictvi-statu/ucetnictvi-podnikatelu-a-neziskoveho-sek/aktuality-a-metodickapodpora/2018/sdeleni-ministerstva-financi-kuctovani-31864 
Short, J. H. (2014). The Future of Cryptocurrency, 1-15. http://www.harkell.com/TFOC-30-03-14.pdf

Smales, L. A. (2020). One Cryptocurrency to explain them all? Understanding the importance of Bitcoin in Cryptocurrency returns. Economic $\mathrm{Pa}$ pers: A journal of applied economics and policy, 39(2), 118-132. . https://doi.org/10.1111/17593441.12282

Swan, M., \& Filippi, P. (2017). Toward a philosophy of blockchain: A symposium: Introduction. Metaphilosophy, 48(5), 603-619. https://doi.org/10.1111/ meta. 12270

Vašek, L. (2018). Recognition and measurement of cryptocurrencies in financial statements prepared in accordance with the IFRS. Accounting and Auditing in the Process of International Harmonization: Proceedings from International Scientific Conference, Janské Lázně, 4.-6. September 2018, Czech Republic, 157-161.

Venter, H. (2016). Digital currency - A case for standard setting activity. A perspective by the Australian Accounting Standards Board (AASB). Retrieved from: https://www.aasb.gov.au/admin/file/ content102/c3/AASB_ASAF_DigitalCurrency.pdf

Cryptocurrency. (2021). In Wikipedia. https://en..org/ wiki/Cryptocurrency

Zákon č. 213/2018 Z. z. o dani z poistenia (Act No. 213/2018 Coll. on Insurance Tax)

Zákon č. 595/2003 Z. z. o dani z príjmov v znení neskorších predpisov (Act No. 595/2003 Coll. on Income Tax as amended)

Zákon č. 431/2002 Z. Z. o účtovníctve v znení neskorších predpisov (Act No. 431/2002 Coll. on Accounting as amended) 


\section{Appendix}

\section{Figure 1}

Bitcoin Price Evolution till January 215t, 2021

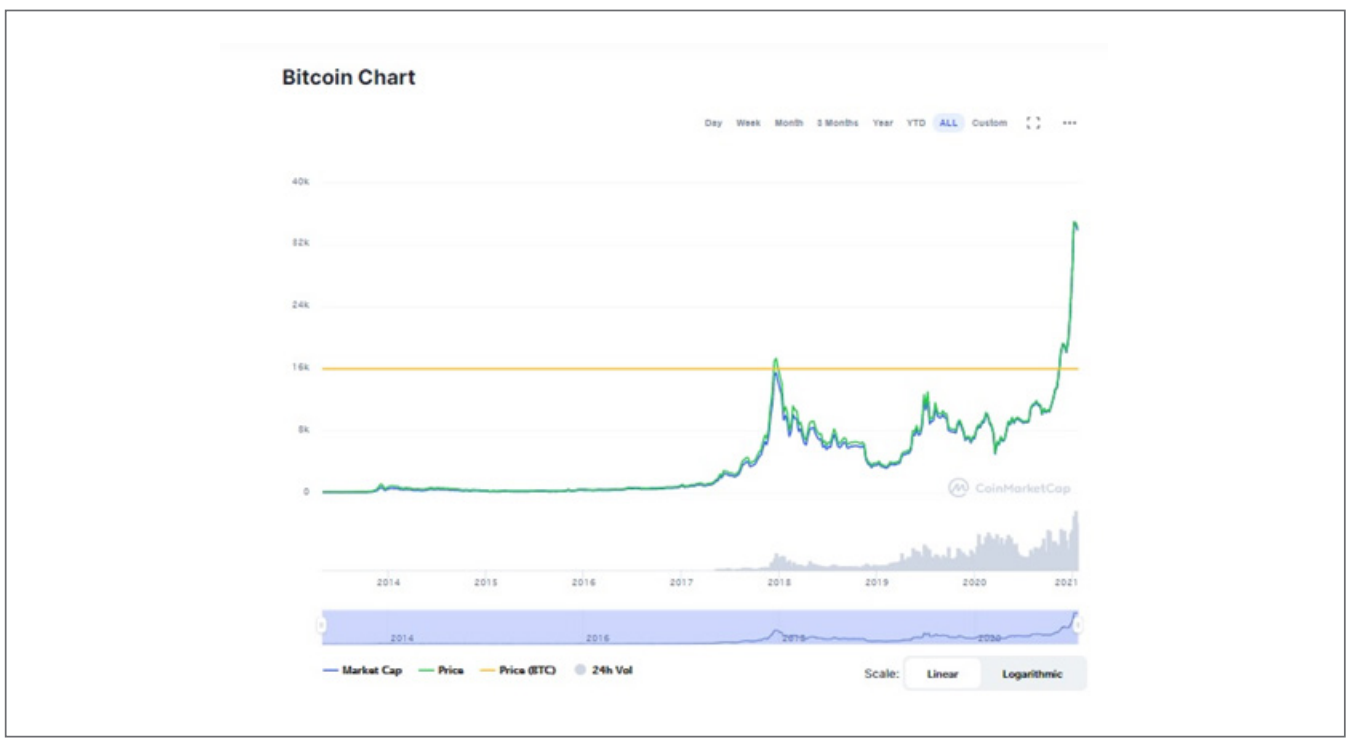

Source: https://coinmarketcap.com/currencies/bitcoin/ 